ATLANTA

Paper ID \#7729

Implications of Problem Based Learning (PBL) in Elementary Schools Upon the K-12 Engineering Education Pipeline

Dr. Daniel Tillman, The University of Texas at El Paso (UTEP) 


\title{
Implications of Problem Based Learning (PBL) in Elementary Schools Upon the K-12 Engineering Education Pipeline
}

\begin{abstract}
This paper examines the effectiveness of a second grade math focused problem based learning (PBL) unit in fostering student interest and collaboration in math through a randomized control design. The study took place in a rural school district in Virginia, where five of the ten elementary schools in the district were selected as intervention schools who received the PBL intervention, and the other five served as control schools who experienced traditional instruction, which in that district consisted primarily of whole class instruction and worksheet completion. The PBL unit charged students with deciding how to spend a sum of money donated by a benefactor to help their local animal shelter. The intervention was designed help students solve the problem through a series of lessons that built upon each other where they learned a variety of relevant math concepts, such as bargain shopping and multiple representations. On a deeper level, students also learned several problem solving skills, including teamwork, researching a topic, formulating evidence based solutions, and presenting their findings. After the unit, all students answered a 22-item engagement survey $(\alpha=.77)$ that asked about their perceptions of and experiences in math (i.e. "Today I explained how I solve math problems to other kids"). Results of a factor analysis indicated the presence of 3 groups of items: Value in Math, Collaboration, and Enjoyment. A subsequent Multivariate Analysis of Variance indicated that PBL students reported significantly higher levels of Collaboration, meaning they worked with and helped their peers more than students in traditional, teacher and worksheet focused instruction. More specifically, students collaborated to solve math problems more than the control group, which involve a set of valuable skills they will need to succeed as engineers and essentially in several STEM careers. Particular components of the PBL unit that encouraged teamwork and collaboration and the engagement survey will also be discussed in detail.
\end{abstract}

\section{Introduction}

Connecting real world problems with academic content is an important part of engineering education, and within this are several opportunities for students to see the connection between several academic subjects and their applicability in the real world, particularly with mathematics ${ }^{1}$. Helping students to learn these connections at early ages can set the foundation for more advanced exercises later in school and possibly give them a jump start in being prepared for challenging careers, including engineering. One instructional method that provides students as young as elementary school with opportunities to make these connections is Problem Based Learning (PBL), where students are responsible for identifying a problem, researching their options, and formulating a solution. These steps are similar to procedures engineers are required to undertake during everyday work ${ }^{2}$, and by integrating this instruction into elementary curricula, students are introduced to and can begin to develop skills that will prepare them to enter the engineering field later in their schooling. One of the key skills students learn through this instruction that is important in engineering programs is teamwork, which is becoming more of an 
emphasis in engineering programs. ${ }^{3,4,5}$ Despite the potential of PBL to help students learn how to work together and apply what they learn to understanding and solving real world problems, few studies have focused on PBL in elementary settings, with many authors calling for more work in this area. ${ }^{6,7,8}$ The current study examined the impact of a PBL unit on engagement (including collaboration, interest in, and value of math, among other components) in second grade students in a rural district in Southwestern Virginia.

\section{Background: Problem Based Learning}

Problem-based learning (PBL) began in medical schools as a means of providing students with real life scenarios they would likely encounter upon entrance into the real world. ${ }^{9}$ PBL could be described as an "Inquiry process that resolves questions, curiosities, doubts, and uncertainties about complex phenomena in life. A problem is any doubt, difficulty, or uncertainty that invites or needs some kind of resolution" (p.3). ${ }^{9}$

Barrows $^{9}$ noted there were six core components of PBL, with five relevant for education (as opposed to medical school). First, activities and learning is centered around the students. In PBL, students are in charge of deciding what was the necessary knowledge they needed to proceed through the steps to solve the problem, figured out where to find it and then obtained this information. Second, students spend most of their time working with only a few of their peers. This setting provided students with opportunities to come together to help each other work out the complexities of the multifaceted problem ${ }^{10}$, develop leadership skills ${ }^{11}$ and where genuine absorption of the material took place.

Third, teachers are tutors and do not lecture the students, explicitly tell students where to find information, or inform students if they were correct if they had questions about their decisions or next steps. Instead of directing students how to move forward and connect material, teachers are responsible for probing students to explain their judgments and created discussions that assisted students in synthesizing information to lead them to theorize problem solutions. ${ }^{11}$

The fourth component of PBL is that the problem served as the center of instruction. That is, the problem represents the focal point of what students were engaged in and served as the motivation for students performing their tasks. The problem is "ill structured," where too little information was given for students to be able to outline clearly defined steps to reach a single correct solution. The final component of PBL is that students gather skills and knowledge from self directed learning, meaning that they manage their own progress and studied in the same manner they would as if they were given this task in the real world.

\section{Prior Research on PBL}

The majority of research on PBL has been done in medical school settings, with little done in K12 populations. While several researchers called for additional studies in these age groups ${ }^{6,7,8}$ research on PBL in education is still in the early stages. A number of studies have found that students who experienced PBL retained more than control students in several subjects including high school biochemistry, American studies, chemistry, and middle school science. ${ }^{12,13,14}$ Evidence is also positive for PBL's ability to help students learn the several steps facets of 
problem solving including identifying the problem, conducting the research, hypothesizing, and testing a solution. ${ }^{15,16}$

Learning in small groups was one of the core components of PBL. ${ }^{17}$ However, little is known about how students worked together or the dynamics that went on in these settings. ${ }^{7}$ Studies that have been done on collaboration have yielded findings that students felt they became better collaborators through working in small groups, enjoyed learning from their peers, improved their ability to articulate their views, and felt a strong sense of accountability and the need to be adequately prepared for their role in the group. ${ }^{15,18}$

\section{Engagement}

Although definitions for engagement vary, researchers have agreed that this is a multidimensional construct. ${ }^{19,20,21}$ For the current study, the framework outlined in Fredricks, Blumenfeld, and Paris' review in 2004 was utilized. ${ }^{20}$ In their review, the authors posited three types of engagement: behavioral engagement, emotional engagement, and cognitive engagement.

Behavioral engagement covers observable student actions and has three areas: positive behavior (i.e., following the rules and not distracting others), participation in class activities (i.e., answering and asking questions), and involvement in school activities such as athletic teams. ${ }^{20}$ Behavioral engagement has been linked to several positive outcomes, particularly higher grades across several populations (i.e., gifted, low income, minority) ${ }^{20}$ Strong behavioral engagement has been associated with several positive outcomes in elementary and middle school students and has been a strong predictor of academic growth. ${ }^{22,23,24}$

Emotional engagement has been defined as student affect during class such as happiness, anxiety, excitement or sadness. ${ }^{20}$ Like behavioral engagement, emotional engagement has been linked with several positive student outcomes, such as student's enthusiasm for their work, decreased likelihood of dropping out, and academic growth. ${ }^{22,25}$

Cognitive engagement has several dimensions that covered internal characteristics including how much students valued what they were learning, the amount of effort students put forth, their motivation to learn the material, and if they regulated their behaviors in order to get their work done. ${ }^{20,21}$ Cognitive engagement has been linked with higher achievement, positive attitudes, and less behavior problems in class. ${ }^{20,26}$ Despite the vast literature described above that illustrated the importance of student engagement, little has been examined on engagement in PBL contexts, particularly in math or with primary age students.

In terms of engagement in PBL, little has been done, but evidence is positive for helping undergraduates engage in cooperative learning and motivation among elementary students in science. ${ }^{8,27}$ While studies on PBL in K-12 settings are emerging, there were clear areas lacking in the current body of literature. Methodologically, few studies utilized elementary aged populations or employed randomized control trials. 


\section{The Current Study}

The current study addressed gaps in the areas of PBL, engagement, and efficacy in math. The sample of second grade students and utilization of a randomized control assignment method helped fill missing methodological gaps, and several relationships were examined that filled in construct related holes. The guiding question for the current study was: Did second grade students who participated in a mathematics based PBL unit report higher levels of engagement compared to students who participated in traditional, teacher directed instruction?

\section{Methods}

The current study was an examination of one piece of a two-year, multifaceted grant. This research project was a Jacob K. Javits initiative funded through the U.S. Department of Education that followed one cohort of students during $2^{\text {nd }}$ and $3^{\text {rd }}$ grade as they experienced three PBL (math or science) units each year.

\section{Setting}

The study took place in one rural county in Southern Virginia. All 10 elementary schools in the division participated with five randomly assigned to serve as intervention schools that would receive the PBL curricula, while the other five were assigned to serve as control schools that implemented routine mathematics instruction. Based on a U.S. Census Bureau 2009 report, the district was high poverty with about $17 \%$ of individuals below the poverty level and a median household income of $\$ 36,000$.

\section{Participants}

Students. The study focused on the second of two math PBL units, and included only students who took the study surveys during this unit's implementation, resulting in 465 students: 231 control and 234 Parallax. Ethnic and gender breakdowns were similar for each group and specific demographic information can be found in Table 1.

Teachers. Sixteen Parallax teachers and 15 control teachers participated. All teachers were female. Demographics of the teachers can be found in Table 2.

Table 1

Demographics of Parallax and Control School Students

\begin{tabular}{llll}
\hline & Control (\%) & Intervention (\%) & Entire Group (\%) \\
\hline Male & 53.1 & 47.7 & 50.9 \\
White & 63.5 & 59.5 & 62.8 \\
Black & 20.2 & 21.6 & 22.4 \\
Hispanic & 12.6 & 11.8 & 12.1 \\
Qualify for & 66.1 & 62.8 & 65.4 \\
Lunch & & & \\
\hline
\end{tabular}


Table 2

Demographics of Parallax and Control School Teachers

\begin{tabular}{lll}
\hline Demographic & Intervention & Control \\
\hline Percent Female & 100 & 100 \\
Average Number of Years Taught & 14.0 & 15.7 \\
Percent with a Master's Degree & 20 & 33 \\
\hline
\end{tabular}

\section{The Intervention}

Project staff developed a mathematics PBL unit that were guided by the Virginia State Department of Education Standards of Learning and the County pacing guide for 2nd grade mathematics. The main components of PBL were described in the prior chapter as outlined by Barrows (1996), ${ }^{9}$ and each of these pieces were included in both units (i.e. small group work, teacher was a guide, student-centered instruction, the problem was the center of all tasks, and work is done through self-directed learning). The current study focuses on the second unit implemented, as the first unit was a pilot that was aimed at gathering information about the students and teachers to use for making the second unit easier for teachers to facilitate and students to engage in.

For Unit Two, students were shown a video from a benefactor who gave them an undisclosed sum of money and were instructed to figure out how to spend it in the best way to help their local Society for the Prevention of Cruelty to Animals (SPCA). Like the first unit, the key concepts of PBL were integrated into the lessons, including small group work, students working on tasks without one correct solution strategy or answer, the problem was the focus of all tasks, teacher was the guide, and students were responsible for making decisions and set the pace for how they moved through their assignments. ${ }^{28}$

For the first couple of lessons, students had to research the SPCA and start thinking about what they would want to buy from a wishlist the organization posted on their website. They used laptops and SPCA brochures and worked together in pairs to note key items the organization would need and begin to think about what they wanted to buy to benefit the charity. To begin to figure out how much money the benefactor donated to their class and in turn how much they could spend, students were given their own set of coins that were part of the class total. In order to count their individual coin total, students were given a set of worksheets that matched an Excel application that had a table next to a bar graph so they could see how their values looked visually on the bar graphs and in numerical form in the tables. Students were put into groups and had to count their own value of each coin and then fill in each other group member's values in the remaining rows in the table and columns in the bar graph. Below is the dimes sheet that has the table on the left and the bar graph on the right: 


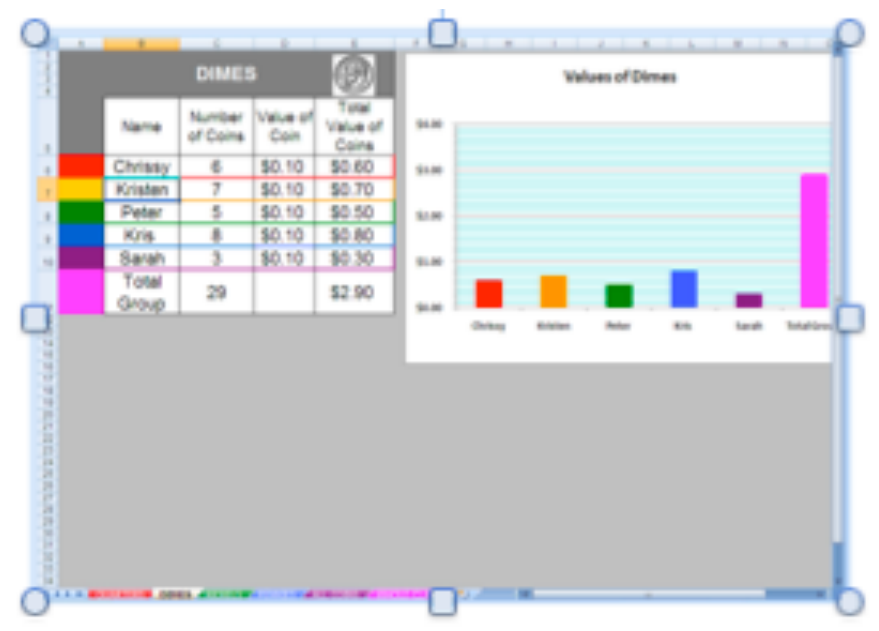

Figure 1: Excel Program with Table and Matching Bar Graph for Dimes

Student worksheets matched the Excel application interface and the components of the application are discussed in the dynamic media section. After figuring out the total value of each type of coin they had, students had a table and graph for their entire group that required them to put in each group member's total of each coin type. Students had to fill out similar pages that gave them tables and graphs that showed the total amount of each coin and the total for their group and class.

The next set of activities required students to shop for possible purchases for the SPCA and to justify why they wanted to buy certain items. The summer before this unit was implemented, Parallax teachers specifically requested integration of pictographs into lessons as these were difficult for students to understand. To integrate them into Unit Two, students had to comparison shop at a drug store and pharmacy the Parallax staff created. To do this, they had to understand that one picture of an item could represent multiple quantities of it (i.e. one picture of cat food represented three that came in one package) and compared where they could get "a better deal" by spending less but getting more items. Like the prior lessons, students had worksheets that matched the interface of computer programs that presented them with room to put in the picture of an item, how many items it represented, pictures of the item, and room for the total amount of items the pictures represented. Students collaborated on these worksheets in the groups they worked with on the Excel exercises and were able to select possible items based on discussing options with their peers. The figure below is from lesson eight when students were first introduced to this concept: 


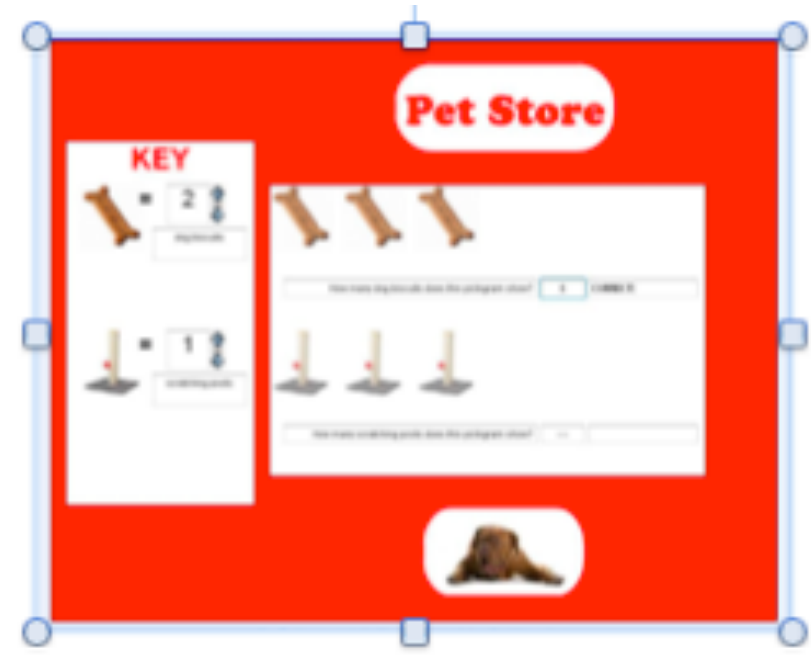

Figure 2: Pet Store Pictograph Activity Page

All of the components of the page could be decided by the students: what items to buy, how many each picture represented, and how many packages to purchase. Near the end of the unit, students were able to do group presentations of they wanted to buy before and the reasons for each item before they voted what to buy as a class, but they had to stay within their class budget. If the total cost for all of the items on the class list went over how much money their class had, they had to figure out how to prioritize and spend less money. Ultimately, the final list of what the students wanted to buy was purchased by Parallax staff and donated to the SPCA.

\section{Data Sources}

Student Surveys. Project staff developed an survey to measure students self reports of their engagement in math. To develop this survey, items were selected from the Research Assessment Package for Schools Elementary Student survey (RAPS-SE; IRRE, 1998) and guided by the engagement framework from Fredricks et al. (2004). ${ }^{20}$ The final survey consisted of 22 items that asked students to rate their perceptions of engagement across the three domains of behavioral, emotional, and cognitive engagement. Example questions were "Today I paid attention in math class" and "Today in math, I worked as hard as I could," which target behavioral and cognitive dimensions, respectively. Cronbach's alpha after administration was .89, indicating acceptable internal reliability. Response options consisted of "A Lot Like Me," "A Little Like Me," and "Not at All Like Me." The complete item list is outlined in the data analysis section.

\section{Procedure}

The unit took place in the winter of 2010 and was 12 lessons long. Inclement weather in the school district resulted in this unit taking longer for many teachers to complete than anticipated, particularly the teachers of focus for the current study. Most teachers finished the unit in less than three weeks, while the two teachers selected for the case studies in the current study taught the second half of lessons twice a week rather than daily. These teachers took six weeks to complete the entire unit. Lessons lasted between 60 and 90 minutes. 
Students filled out the engagement survey near the end of unit implementation. This was done to allow intervention students time to have experienced the unit prior to answering the questions. The control and intervention groups filled out the survey online at their desks, computer labs, or by taking turns on their class computers. Teachers were always on hand to answer questions if necessary. Students finished the survey in an average of 10 minutes.

\section{Results}

Response options to the engagement and self-efficacy surveys were coded with values of 3,2 , or 1 for "A Lot Like Me," "A Little Like Me," and "Not at All Like Me," respectively, and entered into PASW Statistics 18.0. Missing data were handled with multiple imputation.

\section{Factor Analyses}

Exploratory factor analyses (EFA). First, a series of exploratory factor analyses were done to explore how the engagement survey items grouped together. A confirmatory factor analysis followed to evaluate how well the model fit the data.

For the exploratory analyses, a few key standards were used for retaining factors, including eigenvalues above one,${ }^{29}$ scree plots,${ }^{30}$ and the percent of variance accounted for by each factor. Finally, the items present in each factor were evaluated as a whole to determine if they represented a clear underlying construct.

On the item level, those with communalities above .20 and a loading above .30 were retained with their group, and if an item had a loading above .30 on more than one factor, it was retained where it best fit conceptually with the other items in that group. Items that had figures below these benchmarks were not automatically deleted, but instead were compared with the other items in their group and were deleted if they overlapped with another item or did not contribute conceptually to the group. Once all items were evaluated and grouped, each factor was examined as a whole to determine the underlying theoretical construct that described the cluster. All exploratory factor analyses were done using PASW Statistics $18.0^{\mathrm{TM}}$.

After a series of factor analyses that utilized extraction parameters with strict criteria and analyses that did not utilize any, a final three factor model was retained based on how well the items clustered together and alphas of each factor (Table 3). For all analyses, however, principal axis factoring with varimax rotation was used to account for the likely factor correlations. 
Table 3

Retained Factor Model with Items and Communalities

Factor 1: Persistence, Value, Focus $(\alpha=.82)$

$\begin{array}{lll}\text { Today in math class, I worked as hard as I could. } & 0.75 & .58\end{array}$

$\begin{array}{lll}\text { Today I tried very hard at math. } & 0.64 & .50\end{array}$

$\begin{array}{lll}\text { One of my goals in math class is to learn as much as I can. } & 0.58 & .41\end{array}$

$\begin{array}{lll}\text { I tried to figure out hard problems on my own. } & 0.53 & .33\end{array}$

$\begin{array}{lll}\text { Today I understood we learned about in math class. } & 0.48 & .34\end{array}$

$\begin{array}{lll}\text { It is important to me that I understand math. } & 0.45 & .29\end{array}$

$\begin{array}{lll}\text { I paid attention in math class today. } & 0.42 & .26\end{array}$

$\begin{array}{lll}\text { I felt like I could do the math in class today. } & 0.38 & .25\end{array}$

$\begin{array}{lll}\text { I answered questions in math class today. } & 0.37 & .26\end{array}$

Today in math class we worked on challenging problems that

$\begin{array}{lll}\text { made me think hard. } & 0.35 & .24\end{array}$

Factor 2: Working with and Helping Others, Sharing $(\alpha=.79)$

$\begin{array}{lll}\text { I shared my ideas and materials with other kids in math. } & 0.41 & .42\end{array}$

I helped other kids with math today when they didn't know what

$\begin{array}{lll}\text { to do. } & 0.63 & .41\end{array}$

$\begin{array}{lll}\text { Students in my class help each other to learn math. } & 0.62 & .44\end{array}$

Students in my math class worked together to solve problems

$\begin{array}{llll}\text { today. } & 0.59 & .38\end{array}$

$\begin{array}{lll}\text { Today I explained how I solve math problems to other kids. } & 0.56 & .41\end{array}$

Today I wanted to share my answers in class because I thought I

might be right.

$0.53 \quad .30$

I talked about what we are doing in math with someone in my

family (Mom, Dad, Brother, Sister, Grandma) this week. $\quad 0.47 \quad 30$

Factor 3: Enjoyment, Interest $(\alpha=.71)$

$\begin{array}{lll}\text { Math class was fun today. } & 0.43 & .46\end{array}$

$\begin{array}{lll}\text { Today I didn't feel bored in math class. } & 0.56 & .36\end{array}$

I wanted to learn more about what we talked about in math class

In math class today, I didn't think about other things instead of

$\begin{array}{lll}\text { math. } & 0.41 & .26\end{array}$

I didn't give up when math was hard today. $\quad 0.39 \quad .29$

While the factors did not exactly match those outlined in the Fredricks, Blumenfeld, and Paris (2004) review, ${ }^{20}$ evaluation of the item and factor retention indicated a strong and sound three factor model. The eigenvalues were all one, the scree plot had a drop off after the third point, all items loaded strongly on their respective factors and were grouped into sound, reliable constructs. 
Confirmatory Factor Analysis. Once the final model was set, a confirmatory factor analysis (CFA) was done using Mplus 5.0. ${ }^{31}$ Fit statistics suggested the model was a good fit, with a significant chi-square statistic $(p<.001)$ at 352.2, rejecting the hypothesis that the model fit the data, Comparative Fit Index (CFI) of $.96,{ }^{32}$ (close to the desired value of 1) and low Root Mean Square Error of Approximation (RMSEA) was low at $.04 .{ }^{33}$ Each item loaded significantly on its respective factor with all $p$-values less than .001 .

\section{Multivariate Analysis of Variance of Engagement Factors}

To answer the research question that focused on examining differences in engagement by group membership a multivariate analysis of variance (MANOVA) was planned.

Results of the MANOVA indicated there was a significant difference between Intervention and control students on the combined means of the three factors (Wilks $\Lambda=.967 ; p=.001$ ). More specifically, there was a significant difference in the Working with Others factor only $(p=.001)$ with intervention students having higher scores on this construct $(M=16.72)$ than the control group $(M=15.50)$. There was not a significant difference in Persistence, Value, and Focus factor $(p=.59)$, or the Enjoyment and Interest factor $(p=.26)$ by group. The effect size, indicated by partial eta squared $\left(\eta_{\mathrm{p}}{ }^{2}\right)$, was .03, which is between small to medium. ${ }^{34}$ Descriptives can be found in Table 4.

Table 4

Descriptive Statistics for Factors by Group

\begin{tabular}{llllll}
\hline Factor & Group & $\mathrm{N}$ & Mean & $\begin{array}{l}\text { Standard } \\
\text { Deviation }\end{array}$ & $\mathrm{F}(\mathrm{p})$ \\
\cline { 2 - 6 } Persistence, Value, Focus & Control & 231 & 27.20 & 3.58 & $.29(.59)$ \\
& $\begin{array}{l}\text { Intervention } \\
\text { Working with and Helping }\end{array}$ & 234 & 27.27 & 3.03 & \\
Control & 231 & 15.50 & 3.86 & $10.74(.001)^{*}$ \\
& Intervention & 234 & 16.72 & 3.52 & \\
Enjoyment and Interest & Control & 231 & 12.64 & 2.41 & $1.29(.26)$ \\
& Intervention & 234 & 13.0 & 2.13 & \\
\hline
\end{tabular}

$* p<.0056$

\section{Discussion}

Results from the current study indicated that second grade students in a mathematics Problem Based Learning (PBL) context reported higher levels of working with and helping their classmates compared to their peers in traditional, teacher directed instruction. There were no differences between the groups in self-efficacy; however, females across both groups (treatment and control) reported higher levels of all dimensions of engagement: Persistence, Value, and Focus; Working with and Helping Peers, and Value and Interest in the material. 
More specifically, students collaborated to solve math problems more than the control group, which involve a set of valuable skills they will need to succeed as engineers and essentially in several STEM careers.

The current study found that elementary students who experienced PBL reported working with and helping their peers more than students in traditional, teacher directed instruction, suggesting that this instructional approach can have similar outcomes that have been found with older populations. Despite the current study findings that PBL did not impact student value, interest, investment, or enjoyment, findings contribute knowledge about an understudied population in this area and suggest PBL can positively impact student collaboration.

\section{Limitations and Future Research}

Future research should continue to examine PBL in elementary school settings as even though the current study did not yield findings that PBL impacts certain domains of student engagement, research in this area is still very new. This was one setting in a rural district at one point in time and findings may not generalize to other populations. Also, the archival nature of the data did not allow for additional data collection to understand findings or points of interest that arose during data analysis.

\section{Bibliography}

1. Adams, R., Evangelou, D., English, L., de Figueiredo, A., Mousoulides, N., Pawley, A., Schifellite, C., Stevens, R., Svinicki, M., Trenor, J., \& Wilson, D. (2011). Multiple perspectives on engaging future engineers. Journal of Engineering Education, 100(1), 48-88.

2. Rogers, C., \& Portsmore, M. (2004). Bringing engineering to elementary school. J.of STEM Ed, 5 (3,4), 17-28.

3. Adams, S. (2003) Building successful student teams in the engineering classroom. J.of STEM Ed., 4(3,4), 1-6.

4. McNair, L, Newswander, C., Boden, D., \& Borrego, M. (2011). J. of Engineering Education, 100(2), 374-396.

5. Seat, E., Parsons, J., Poppen, W. (2001). Enabling engineering performance skills: A program to teach communication, leadership, and teamwork, 90(1), 7-12

6. Gallagher, S. (1997). Problem-based learning: Where did it come from, what does it do, and where is it going? Journal for the Education of the Gifted, 20, 332-362.

7. Hmelo-Silver, C. (2004). Problem-based learning: What and how do students learn? Educational Psychology Review, 6, 235-266.

8. Zumbach, J., Kumpf, D., \& Koch, S. C. (2004). Using multimedia to enhance problem- based learning in elementary school. Information Technology in Childhood Education Annual,1, 25-37.

9. Barrows, H. (1996). Problem-based learning in medicine and beyond: A brief overview. New Directions for Teaching and Learning, 68, 3-12.

10. Prince, M. (2004). Does active learning work? A review of the research. Journal of Engineering Education, 93, 
11. Duek, J. (2000). Whose group is it anyway? Equity of student discourse in problem-based learning (PBL). In Hmelo, C., \& Evensen, D. (Eds). Problem-based learning: A research perspective on learning interactions (pp. $75-$ 107). Lawrence Erlbaum Associates, Mahwah, NJ.

12. Dods, R. (1997). An action research study of the effectiveness of problem-based learning in promoting acquisition and retention of knowledge. Journal for the Education of the Gifted, 20, 423-437.

13. Liu, M., Hsieh, P., Cho, Y., \& Schallert, D. (2006). Middle school students' self-efficacy, attitudes, and achievement in a computer-enhanced problem-based learning environment. Journal of Interactive Learning Research, 17, 225-242.

14. Senocak, E., Taskesenligil, Y., \& Sozbilir, M. (2007). A study on teaching gases to prospective primary science teachers through problem based learning. Research in Science Education, 37, 279-290.

15. Cockrell, K., Caplow, J., \& Donaldson, J. (2000). A context for learning: Collaborative groups in the problembased learning environment. The Review of Higher Education, 23, 347-363.

16. Gallagher, S., Stepien, W., \& Rosenthal, H. (1992). The effects of problem-based learning on problem solving. Gifted Child Quarterly, 36, 195-200.

17. Barell, J. (1997). Problem-based learning: An inquiry approach. Thousand Oaks, CA: Corwin Press.

18. Cerezo, N. (2004). Problem-based learning in the middle school: A research case study of the perceptions of atrisk females. Research in Middle Level Education, 27, 1-13.

19. Appleton, J., Christenson, S., \& Furlong, M. (2008). Student engagement with school: Critical conceptual and methodological issues of the construct. Psychology in the Schools, 45, 369-386.

20. Fredricks, J., Blumenfeld, P., \& Paris, A. (2004). School engagement: Potential of the concept, state of the evidence. Review of Educational Research, 74, 59-109.

21. Jimerson, S., Campos, E., \& Greif, J. (2003). Toward an understanding of definitions and measures of school engagement and related terms. California School Psychologist, 8, 7-27.

22. Bodovski, K., \& Farkas, G. (2007). Mathematics growth in early elementary school: The roles of beginning knowledge, student engagement, and instruction. The Elementary School Journal, 108, 115-130.

23. Hughes, J., Luo, W., Kwok, O., \& Loyd, L. (2008). Teacher-student support, effortful engagement, and achievement: A 3-year longitudinal study. Journal of Educational Psychology, 100, 1-14.

24. Ponitz, C., Rimm-Kaufman, S., Grimm, K., \& Curby, T. (2009). Kindergarten classroom quality, behavioral engagement, and reading achievement. School Psychology Review, 38, 102-120.

25. Alexander, K., Entwisle, D., \& Horsey, C. (1997). From first grade forward: Early foundations of high school dropout. Sociology of Education, 70, 87-107.

26. Meece, J., Glienke, B., \& Burg, S. (2006). Gender and motivation. Journal of School Psychology, 44, $351-373$.

27. Ahlfeldt, S., Mehta, S., \& Sellnow, T. (2005). Measurement and analysis of student engagement in university classes where varying levels of PBL methods of instruction are in use. Higher education Research and Development, 24, 5-20.

28. Barrows, H., \& Tamblyn, R. (1980). Problem-based learning: An approach to medical education. New York, 
NY: Springer.

29. Kaiser, H. F. (1960). The application of electronic computers to factor analysis. Educational and Psychological Measurement, 20, 141-151.

30. Cattell, (1966)

31. Muthén, L. K., \& Muthén, B. O. (2007). Mplus User’s Guide (5th ed). Los Angeles, Muthén, \& Muthén

32. Bentler, P.M. (1990). Comparative fit indices in structural models. Psychological Bulletin,107, 238-246.

33. Browne, M.W., \& Cudeck, R. (1993). Alternative ways of assessing model fit. In L.G. Grimm \& P.R. Yarnold (Eds.), Testing Structural Equation Models. Newbury Park, CA: Sage.

34. Cohen, J. (1977). Statistical power for the behavioral sciences. New York: Academic Press.

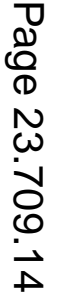

